ISSN 0103-5150

Fisioter. Mov., Curitiba, v. 26, n. 3, p. 579-585, jul./set. 2013

Licenciado sob uma Licença Creative Commons

\title{
Association between work engagement and perceived exertion among healthcare workers
}

\author{
Associação entre o compromisso com o trabalho e a \\ percepção de esforço físico em profissionais da saúde
}

\section{Rodrigo Luiz Carregaro ${ }^{[a]}$, Aline Martins de Toledo ${ }^{[a]}$, Gustavo Christofoletti ${ }^{[a]}$, Ana Beatriz de Oliveira ${ }^{[b]}$, Jefferson Rosa Cardoso ${ }^{[c]}$, Rosimeire Simprini Padula ${ }^{[d]}$}

[a] PT, PhD, professor at the School of Physical Therapy, Federal University of Mato Grosso do Sul (UFMS), Campo Grande, MS - Brasil, e-mails: rodrigocarregaro@yahoo.com.br, toledo_am@yahoo.com.br, gustavo_physio@yahoo.com.br

[b] PT, PhD, professor at the Department of Physical Therapy, Federal University of São Carlos (UFSCar), São Carlos, SP Brasil, email: biaoliveira@gmail.com

[c] PT, PhD, professor at the Department of Physical Therapy, State University of Londrina (UEL), Londrina, PR - Brasil, e-mail: jeffcar@uel.br

[d] PT, PhD, professor at the School of Physical Therapy, São Francisco University (USF), Graduate Program in Physical Therapy, City University of São Paulo (Unicid), São Paulo, SP - Brasil, e-mail: rosipadula@gmail.com

\section{Abstract}

Introduction: Complaints and musculoskeletal discomforts are common manifestations of individuals affected by work-related disorders (WRMD), and the influence of individual and/or psychosocial risk factors may play a significant role in WRMD development. Objective: To evaluate and to compare work engagement (WE) and ratings of perceived exertion (RPE) and to assess the association between indexes of WE and RPE among healthcare workers. Materials and methods: Seventeen female subjects ( $36 \pm 11$ years, $1.58 \pm 0.06$ $\mathrm{m}$ and $59 \pm 9 \mathrm{~kg}$ ) participated, all officially employed on a nonprofit agency. The Nordic Questionnaire was used to evaluate musculoskeletal complaints and the Borg Scale used to evaluate the RPE. The Utrecht Work Engagement Scale quantified WE (vigor, dedication and absorption domains). Participants were divided into two groups, according to their sectors: healthcare clinics and institution for the elderly. The independent student $t$ test was used to verify differences between groups and the chi-square test to verify associations between variables. Results: All subjects reported musculoskeletal complaints, mainly in the low back (58\%). RPE did not differ between groups, while in the vigor, it was found a significant statistically difference 
$(p=0.035)$. An association between RPE and vigor and RPE and dedication was establish $(p=0.02$ and $p=0.036$, respectively). Conclusion: The association between WE and RPE suggests that workers with lower indexes of vigor and dedication may perceive greater physical demand, which can be imposed by work demands.

Keywords: Ergonomics. Physical exertion. Quality of life. Workplace.

\section{Resumo}

Introdução: Queixas e desconforto musculoesquelético são manifestações comuns de indivíduos afetados por doenças relacionadas ao trabalho (DORT), e a influência de fatores individuais e ou fatores de risco psicossociais podem desempenhar um papel significativo no desenvolvimento das DORT. Objetivo: Avaliar o compromisso com o trabalho (CT) e o esforço percebido (RPE), além de avaliar a associação entre os índices de CT e RPE entre trabalhadores da área da saúde. Materiais e métodos: Participaram 17 mulheres (36 \pm 11 anos, 1,58 $\pm 0.06 \mathrm{~m}$ e $59 \pm 9 \mathrm{~kg}$ ), funcionárias registradas de uma entidade beneficente. Foram utilizados o Questionário Nórdico de Sintomas e a escala de Borg para avaliar, respectivamente, as queixas de desconforto musculoesquelético e o esforço percebido. A escala de compromisso com o trabalho (Utrecht Work Engagement Scale) quantificou o CT (domínios vigor, dedicação e interesse). Os participantes foram divididos em dois grupos, baseado em seus setores: clínicas e instituição de idosos. $O$ teste $t$ de Student para amostras independentes foi aplicado para verificar diferenças entre grupos e o teste Qui-quadrado para verificar associações entre as variáveis. Resultados: Todos os participantes relataram desconforto musculoesquelético, principalmente na coluna lombar (58\%). O RPE não apresentou diferença entre grupos, enquanto o vigor apresentou diferença significante $(p=0,035)$. Foi encontrada associação entre RPE e vigor entre RPE e dedicação ( $p=0,02$ e $p=0,036$, respectivamente). Conclusão: $A$ associação entre o CT e o RPE sugere que trabalhadores com baixos índices de vigor tendem a perceber maior demanda física, a qual pode ser imposta por diferentes processos de trabalho.

Palavras-chave: Ergonomia. Esforço físico. Qualidade de vida. Local de trabalho.

\section{Introduction}

Work-related musculoskeletal disorders are not job-specific and affect workers in a wide variety of occupations. These disorders usually take months or even years to develop and are a major cause of lost time from work, compensation claims and health care costs (1), and can result in pain, loss of functional capacity and work disability. Furthermore, work related musculoskeletal disorders have a multifactorial etiology, including physical, organizational and individual factors and can correspond to an assortment of clinical diagnoses (2).

Complaints and musculoskeletal discomforts are common manifestations of individuals affected by workrelated disorders (3). In this sense, Borg (4) states that the degree of physical effort exerted during work is of interest to ergonomics professionals, considering that it is important to understand the effect of workplace and occupational activities on performance, work capacity and health. Walsh et al. (5) affirms that use instruments that provide information about functional deficit has become necessary, considering the great impact of work-related musculoskeletal disorders on workers' abilities and health. Moreover, Hughes (6) suggest that the influence of individual and/or psychosocial risk factors may play a significant role in work-related musculoskeletal disorders development. In this sense, perceived exertion could be a useful index of workload and subjective experience of both time load and mental effort load (6). For instance, Raffone et al. (7) attributed the high prevalence of injuries in nursing to the fact that musculoskeletal diseases were higher in groups of employees with reduced work capacity due to conditions of both physical and emotional overload during the performance of their tasks.

The subjective perceptions of workers about job demands as a result of the physical characteristics of the load, the environment, their personality and previous experiences have been termed work-related psychophysical factors. According to Schaufeli et al. (8), the commitment or engagement to work is a psychometric variable that has been the focus of several studies 
because it can provide important information about human capability, especially workplace performance. Therefore, the work engagement as adopted in the context of the present study was determined by Schaufeli and Bakker (9) as "a state of mind related to work, which is positive and satisfactory, marked by vigor, dedication and absorption during the performance of occupational activities".

It is important to point out that organizational and psychosocial factors play an important role in the genesis and evolution of musculoskeletal complaints (10), and that the interaction between cognitive and physical factors must be integrated into an ergonomic evaluation so that global and effective preventive actions are promoted in the occupational environment. The aim of the present study, therefore, was to evaluate and to compare work engagement and ratings of perceived exertion (RPE) between two groups of healthcare workers directly involved with users of the health system of a nonprofit agency. The secondary aims were to determine the association between the domains of work engagement (vigor, dedication and absorption) and RPE during occupational activities performed by these healthcare workers; and to characterize the musculoskeletal symptoms.

\section{Materials and methods}

\section{Participants}

A convenience sample of seventeen healthy female subjects $(36 \pm 11$ years, $1.58 \pm 0.06 \mathrm{~m}$ and 59 $\pm 9 \mathrm{~kg}$ ) was recruited to participate in the study. All workers were employed in two healthcare centers of a nonprofit agency. Due to limited staff in the analyzed sectors, the sample size was restricted. Subjects were included if they presented (i) at least one year of occupational experience; (ii) if they were official regular employees of the institution; and (iii) at least 18 years old. Subjects were excluded if they presented orthopedic problems in the preceding six months and if they didn't want to participate.

Group division was according to work sector. During the study, the nonprofit agency ran two healthcare clinics and one institution for the elderly. Thus, two groups were formed: (i) healthcare clinics ( $\mathrm{n}=9)(\mathrm{HC})$ and (ii) institution for the elderly ( $n=8$ ) (IE), whose job descriptions were both characterized by daily client support. All of the studied employees had a 6 to 8 hour workday.
The study protocol was approved by the institutional review board (protocol n. 1658/2010), and all subjects gave informed consent before participation.

\section{Musculoskeletal symptoms}

In order to record musculoskeletal symptoms related to work, a validated version of the Nordic Questionnaire was applied $(11,12)$. The questionnaire was adapted using structured and semi-structured questions that addressed personal data and musculoskeletal workrelated symptoms from the past 12 months and the previous week. A body diagram (Figure 1) was used, and all participants were instructed to point out one or more body regions in which discomfort was present. The visual analog scale (VAS) was applied in order to quantify the magnitude of musculoskeletal discomfort. For the VAS, participants selected one body region that was, in their opinion, the most affected, and marked a point that best represented the intensity of discomfort in a line with exactly $10 \mathrm{~cm}$ ( 0 being no pain and 10 the worst pain ever). The VAS was measured in centimeters $(\mathrm{cm})$, considering the demarcation of each individual.

\section{Perceived exertion}

Ratings of perceived exertion were measured with the Borg RPE Scale5, based on the physical demands of their characteristic working processes. RPE scores can vary from 6 ("no exertion at all") to 20 ("maximum effort"), which represents workers' physical effort during the performance of their occupational activities. Verbal anchors are provided in order to standardize for comparison across individuals and tasks.

\section{Work engagement}

Work engagement and individual notions of commitment to work were evaluated according to the Utrecht Work Engagement Scale (UWES) (9). The total score is computed by summing the score for each sub-category: (i) vigor, characterized by high levels of energy and persistence during work even tough difficulties are present; (ii) dedication, characterized by a significant involvement with the work, i.e., pride, enthusiasm and sense of challenge from the activities; and (iii) absorption, characterized by full concentration on the job. Higher 
scores indicate a better classification of work engagement, which can analyzed numerically or be verbally expressed as very low, low, regular, high or very high, as determined by the final score.

\section{Occupational activities}

Although the activities performed by the two groups differed, they can both be characterized by daily contact with clients and patients of their respective institution. Activities performed at the healthcare clinic included daily public support and the scheduling of medical and dental care. This group of workers was composed of administrative technicians, who performed their activities in a seated posture for prolonged periods: filling out forms, organizing archives and structuring the daily health assistance schedule. Workers from the institution for the elderly were nurses and technicians, responsible for elderly residents. Their activities included daily hygiene care, feeding and drug administration, measuring vital signs, manual handling of dependent patients and bed/wheelchair transferences.

\section{Data analysis}

Data was expressed by mean and standard deviation because of its normal distribution, as verified by the Shapiro-Wilk test. Musculoskeletal symptoms were analyzed descriptively. Subjects were divided into two groups: (i) health clinics (HC) and (ii) institution for the elderly (IE); between-group comparisons were analyzed using the student $t$ test for independent samples in order to verify differences between RPE and work engagement. The association between RPE and work engagement was investigated by the chi-square test. The Statistical Package for Social Sciences (SPSS) software version 13.0 was used for statistical analysis, with significance set at $5 \%(\mathrm{p}<0.05)$.

\section{Results}

With respect to musculoskeletal symptoms, all subjects reported work-related complaints in several body regions during the previous 12 months as well as the previous week (Figure 1). The highest frequency of response was related to the low back, with a prevalence of $58 \%$ for both the past 12 months as for the previous

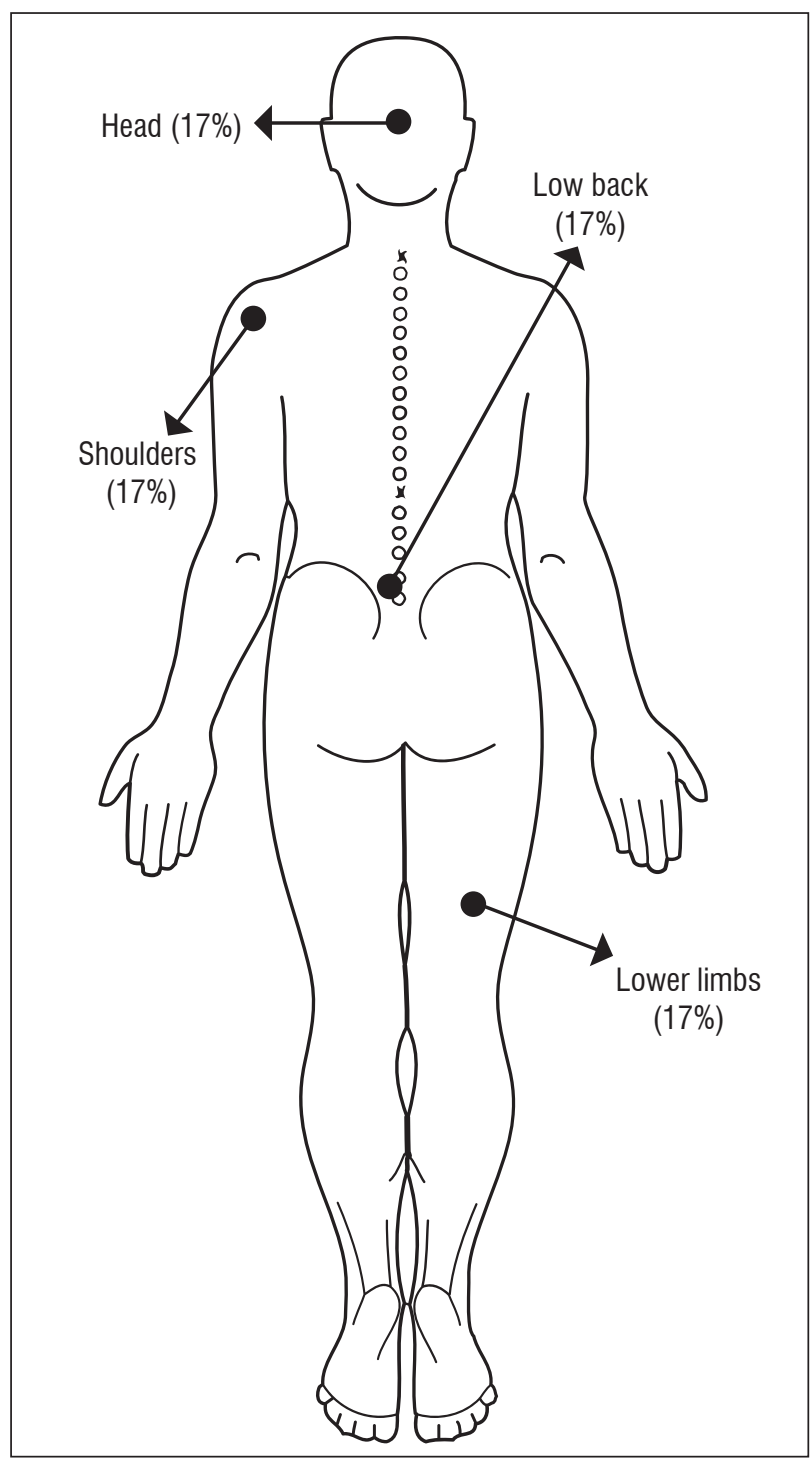

Figure 1 - Frequencies of musculoskeletal symptoms for the past 12 months and the previous week

Source: Research data.

Note: Frequencies represent total responses, considering that workers indicated more than one anatomic region.

week. In respect to VAS values, participants presented a mean intensity of $8 \pm 2 \mathrm{~cm}$. Considering group division, subjects from HC presented a mean VAS of $7.3 \pm 1.5 \mathrm{~cm}$. For the IE, the mean VAS was $7.8 \pm 2.0 \mathrm{~cm}$. There was no significant differences between IE and HC $(p=0.6)$.

Findings related to the distribution of RPE as measured by the Borg scale demonstrated that mean RPE ratings of the $\mathrm{HC}$ group was $12 \pm 1$ (classified between "light" and "somewhat hard"). On the other hand, workers from the IE reported a higher mean RPE value of $14 \pm 2$ (classified between "somewhat hard" 
and "hard"). However, differences between groups were not statistically significant $(\mathrm{p}=0.17)$.

Table 1 presents findings related to scores from work engagement of HC and IE. Work engagement presented significant differences between groups in the vigor domain. When compared to HC workers, workers from the IE presented statistically higher indices of vigor $(p=0.035)$. Dedication and absorption were the same for both groups $(\mathrm{p}=0.06$ and $\mathrm{p}=0.67$, respectively).

There was a significant association found in the present study for RPE and vigor domain $\left(\chi^{2}=7.43\right.$; $\mathrm{p}=0.02)$ and RPE and dedication domain $\left(\chi^{2}=10.28\right.$; $p=0.036)$. The absorption domain of work engagement did not present any significant association with $\operatorname{RPE}\left(\chi^{2}=2.47 ; \mathrm{p}=0.3\right)$.

\section{Discussion}

The purpose of this study was twofold: first, to determine whether work engagement and perceived exertion were different between healthcare workers of a nonprofit agency; second, to determine if work engagement was associated with RPE measurements between these healthcare workers. RPE did not differ between groups, and the main finding was that workers' vigor and dedication presented a significant association with perceived exertion. Some arguments will be presented to explain these results.

The high prevalence of complaints and discomfort found in our study, mainly associated with the low back, and the high intensity of discomfort demonstrated by VAS measures, can be explained by the risk factors presented in the occupations analyzed. Even though physical variables such as posture or inadequate furniture were not the focus of our study, recognizing their role as important risk factors for
WRMD is one of the bases for wider and more effective ergonomic interventions for musculoskeletal injury prevention (13), and might explain these findings. In fact, occupational activities performed during prolonged sitting, as observed in $\mathrm{HC}$, may have an important influence on the genesis of occupational low back pain, especially if associated with asymmetrical and static postures $(13,14)$. Considering that the clients of the IE group were elderly permanent residents, a daily routine of situations involving physical and mental stress came into play. Factors such as patient handling (15) and lack of rest (16) could explain the high rates of complaints recorded among IE workers. The application of the biopsychossocial model of illness to the context of occupational low back pain should also be considered (17), as well as factors such as motivation and anxiety, which would facilitate an overview of healthcare work processes in ergonomics analysis and interventions, and should be addressed in future studies.

Regarding RPE, the absence of intergroup difference confirmed that the job functions, despite differing circumstances and demands, produced the same perception of physical overload, which should be interpreted as an important risky condition. This fact might be supported by the study of Sengupta and Das (18), which evaluated normal, maximum and extreme workspaces for light manipulative tasks and demonstrated that even a simple variable as reach distance played a significant role on worker physiological cost and, consequently, on occupational hazards. Also, Liu et al. (19) demonstrated that simple mental tasks, such as serial subtractions, can impose higher blood pressure and higher vascular resistance.

Considering that activities performed by workers in our study also encompassed manipulative and mental tasks, the same perception of physical

Table 1 - Mean scores (and respective nominal classifications) from work engagement (UWES) for Health Clinics (HC) and Institution for the Elderly (IE) (mean \pm standard deviation)

\begin{tabular}{lclllc}
\hline & HC & Classification & IE & Classification & p \\
\hline Vigor & $4.31 \pm 0.36$ & Average & $5.03 \pm 0.75$ & High & $0.035^{*}$ \\
Dedication & $3.58 \pm 0.74$ & Average & $4.90 \pm 1.24$ & Average & 0.06 \\
Absorption & $4.17 \pm 0.76$ & Average & $3.97 \pm 0.72$ & Average & 0.70 \\
\hline
\end{tabular}

Legend: * = significant difference.

Source: Research data. 
overload and the significant association between vigor and RPE provides relevant information about occupational demands. Subjects who had lower scores of vigor evaluated their activities as more physically intense, indicating that the psychometric scale of Work Engagement can be useful when combined with instruments more focused on the physical demands of work, and corroborates with Waters (20), who demonstrated the importance of understanding how excessive work demands can lead to increased risk of work-related musculoskeletal disorders. These findings may be relevant to the extent that prolonged exposure to adverse physical conditions might determine the onset of WRMD and corroborates with other studies $(6,13,14,18,19)$.

According to Schaufeli and Bakker (9) the concept of work engagement is the opposite of what happens to workers affected by the burnout syndrome. Subjects who are stimulated and pleased with their work feel capable of and excited about performing it. In the present study, scores related to vigor were significantly lower in HC than IE. Perhaps human contact might explain higher levels of vigor found among IE workers, considering the fact that this type of function can also bring benefits, such as satisfaction, as a result of aiding dependent patients (17). Workers' dedication presented a significant association with RPE measures, demonstrating that lower indexes of dedication were also associated with an increased perception of physical strain during work. In this sense, Demerouti et al. (21) showed that commitment level is positively associated with health, i.e., to low levels of depression and complaints. Although "work content" was not measured in the present study, we observed that the activities of the HC group were not especially challenging work, which raises the possibility that causal factors related to stress and burnout were present, including motivational issues or depression, and could explain influences on workers' dedication. Further studies could focus on these variables to clarify their influence on vigor, dedication, absorption and their associations with perceived exertion among healthcare workers. Furthermore, future studies should examine characteristics related to physical performance, such as aerobic fitness, considering that in our study we observed that $71 \%$ of the participants were sedentary. This could help understanding of other influences on occupational overload for this type of worker, besides helping to increase their quality of life.
A limitation of the study is the small sample size. As mentioned above, the use of a larger sample was impeded by the limited staff size in the analyzed healthcare settings. It is worthy of note that for studies involving evaluations of real strategies and demands in the workplace, a low subject number is a inevitable limitation, mostly due to staff reductions or financial problems, which have occurred in both industrial and service sectors of several companies and institutions. Nonetheless, as our study focused on healthcare work processes, the generalization of our findings to other professional environments where there are similar functions and features could be considered.

\section{Conclusion}

The present study indicated that perceived exertion did not differ between groups of healthcare workers, even though some occupational activities were distinct. Findings also suggest that the study of work engagement and RPE should be included as important variables of a wider analysis of ergonomics, considering that workers with lower vigor and dedication scores may report higher ratings of physical demand imposed by their functions and inherent demands.

\section{References}

1. Franco G, Fusetti L. Bernardino Ramazzini's early observations of the link between musculoskeletal disorders and ergonomic factors. Appl Ergon. 2004;35(1):67-70.

2. Walsh IAP, Oishi J, Coury HJCG. Clinical and functional aspects of work-related musculoskeletal disorders among active workers. Rev Saúde Pública. 2008;42(1):108-16.

3. Augusto VG, Sampaio RF, Tirado MGA, Mancini MC, Parreira VF. Um olhar sobre as LER/DORT no contexto clínico do fisioterapeuta. Rev Bras Fisioter. 2008;12(1):49-56.

4. Borg G. Borg's perceived exertion and pain scales. Champaign: Human Kinetics; 1998. 
5. Walsh IAP, Corral S, Franco RN, Canetti EF, Alem MER, Coury HJCG. Work ability of subjects with chronic musculoskeletal disorders. Rev Saúde Pública. 2004;38(2):149-56.

6. Hughes L, Babski-Reeves K, Smith-Jackson T. Effects of psychosocial and individual factors on physiological risk factors for upper extremity musculoskeletal disorders while typing. Ergonomics. 2007;50(2):261-74.

7. Raffone AM, Hennington EA. Avaliação da capacidade funcional dos trabalhadores de enfermagem. Rev Saúde Pública. 2005;39(4):669-76.

8. Schaufeli W, Bakker A, Salanova M. The measurement of work engagement with a short questionnaire: a cross-national study. Educ Psychol Meas. 2006;66(4):701-16.

9. Schaufeli W, Bakker A. UWES - Utrecht work engagement scale: preliminary manual. Utrecht: Occupational Health Psychology Unit, Utrecht University; 2003 [cited 12 Ago 2013]. Available at: http://www. beanmanaged.com/doc/pdf/arnoldbakker/articles/ articles_arnold_bakker_87.pdf

10. Monteiro MS, Alexandre NMS, Rodrigues CM. Musculoskeletal diseases, work and lifestyle among public workers at a health institution. Rev Esc Enferm USP. 2006;40(1):20-25.

11. Kuorinka I, Jonsson B, Kilbom A, Vinterberg H, Biering-Sorensen F, Andersson G, et al. Standardised Nordic questionnaires for the analysis of musculoskeletal symptoms. Appl Ergon. 1987;18(3):233-7.

12. Barros ENC, Alexandre NMC. Cross-cultural adaptation of the Nordic musculoskeletal questionnaire. Int Nurs Rev. 2003;50(2):101-8.

13. Vieira ER, Kumar S. Working postures: a literature review. J Occup Rehabil. 2004;14(2):143-59.
14. Lis AM, Black KM, Korn H, Nordin M. Association between sitting and occupational LBP. Eur Spine J. 2007;16(2):283-98.

15. Alexandre NMC, Rogante MM. Movimentação e transferência de pacientes: aspectos posturais e ergonômicos. Rev Esc Enferm USP. 2000;34(2):165-73.

16. Carvalho G, Lopes S. Nursing professional satisfaction in a general hospital emergency unit. Arq Cienc Saúde. 2006;13(4):215-19.

17. Weiner BK. Spine update: the biopsychosocial model and spine care. Spine. 2008;33(2):219-23.

18. Sengupta AK, Das B. Determination of worker physiological cost in workspace reach envelopes. Ergonomics. 2004;47(3):330-42.

19. Liu X, Iwanaga K, Shimomura Y, Katsuura T. Different types of circulatory responses to mental tasks. J Physiol Anthropol. 2007;26(3):355-64.

20. Waters TR. Introduction to ergonomics for healthcare workers. Rehabil Nurs. 2010;35(5):185-91.

21. Demerouti E, Bakker AB, Janssen PPM, Schaufeli WB. Burnout and engagement at work as a function of demands and control. Scand J Work Environ Health. 2001;27:279-86.

Received: $10 / 12 / 2012$ Recebido: 12/10/2012

Approved: 05/10/2013 Aprovado: 10/05/2013 